\title{
Predictors of Impaired Survival in Subjects With Long-Term Oxygen Therapy
}

\author{
Heidi A Rantala, Sirpa Leivo-Korpela, Lauri Lehtimäki, and Juho T Lehto
}

\begin{abstract}
BACKGROUND: The need for long-term oxygen therapy (LTOT) is usually a sign of advanced disease, which could trigger advance care planning. However, LTOT is used in patients with different characteristics and multiple diagnoses beyond COPD. We studied the factors associated with survival in an unselected sample of subjects who started LTOT. METHODS: We conducted a retrospective study that included 195 subjects for whom LTOT was initiated in Tampere University Hospital from January 1, 2012, to December 31, 2015, and followed up until December 31, 2017. RESULTS: The most frequent diseases that caused the need for LTOT were COPD and interstitial lung diseases. Most of the subjects $(69 \%)$ died during the study period; the median survival time was $2.2 \mathrm{y}$. The subjects with interstitial lung disease as a primary disease for LTOT had a shorter survival time (median $0.9 \mathrm{y}$ ) compared with those with COPD (median $2.4 \mathrm{y}, P<.001$ ). Survival was shorter in the subjects ages $>75 \mathrm{y}$ (median $1.4 \mathrm{y}$ ) compared with those who were ages $\leq 75 \mathrm{y}$ (median $2.8 \mathrm{y}, P=.001$ ) and also in those who required help with daily activities (median 1.2 y) compared with those who did not (median $3.3 \mathrm{y}, P<.001$ ). In multivariate analysis, a diagnosis of interstitial lung disease (hazard ratio 2.1, 95\% CI 1.4-3.2), Charlson comorbidity index (hazard ratio 1.26, 95\% $\mathrm{Cl}$ 1.11-1.43), and required help in activities of daily living (hazard ratio 2.1, 95\% CI 1.4-3.1) were associated with impaired survival. CONCLUSIONS: The survival of the subjects who started LTOT varied greatly. The subjects with interstitial lung disease and those who required assistance with activities of daily living were at risk of dying in $\sim 1 \mathrm{y}$, which suggested that advance care planning should be directed especially to these patients. Key words: chronic hypoxemia; long-term oxygen therapy; interstitial lung disease; chronic obstructive pulmonary disease; activities of daily living; survival. [Respir Care 2019;64(11):1401-1409. () 2019 Daedalus Enterprises]
\end{abstract}

\section{Introduction}

Chronic hypoxemia is a common feature in many endstage respiratory diseases. Long-term oxygen therapy

Dr Rantala and Dr Leivo-Korpela are affiliated with the Department of Respiratory Medicine, Tampere University Hospital, Tampere, Finland. Dr Rantala, Dr Leivo-Korpela, Dr Lehtimäki, and Dr Lehto are affiliated with the Faculty of Medicine and Health Technology, Tampere University, Tampere, Finland. Dr Lehtimäki is affiliated with the Allergy Centre, Tampere University Hospital, Tampere, Finland. Dr Lehto is affiliated with the Palliative Care Unit, Department of Oncology, Tampere University Hospital, Tampere, Finland.

The study was supported by grants from Medical Research Fund of Tampere University Hospital, Väinö and Laina Kivi Foundation, Tampere Tuberculosis Foundation, The Research Foundation of the Pulmonary Diseases, Nummela Foundation, Jalmari and Rauha Ahokas Foundation, and The Finnish Anti-tuberculosis Foundation.
(LTOT) can be used to treat hypoxemia, but the effects of LTOT on survival and precise indications for it have been assessed only in subjects with COPD. LTOT prolongs survival and is recommended in patients with COPD who have severe hypoxemia, defined as $\mathrm{P}_{\mathrm{aO}_{2}} \leq 55 \mathrm{~mm} \mathrm{Hg}$ or $\mathrm{P}_{\mathrm{aO}_{2}}$ between 55 and $60 \mathrm{~mm} \mathrm{Hg}$ in the presence of complicating factors, such as peripheral edema, polycythemia (hematocrit $\geq 55 \%$ ) or pulmonary hypertension. ${ }^{1-3}$ There

\footnotetext{
The authors have disclosed no conflicts of interest.

Correspondence: Heidi A Rantala MD, Department of Respiratory Medicine, Tampere University Hospital, Faculty of Medicine and Health Technology, Tampere University, Teiskontie 35, 33521 Tampere, Finland. E-mail: Heidi.Rantala@tuni.fi.
}

DOI: $10.4187 /$ respcare. 06615 
is clear evidence for LTOT usage in patients with COPD and with these criteria, but LTOT does not seem to improve survival in patients with COPD and with moderate hypoxemia only. ${ }^{4-7}$

Although the best evidence for the use of LTOT is based on studies in subjects with COPD, LTOT is also recommended in many other diseases that cause hypoxemia (interstitial lung disease, cystic fibrosis, pulmonary hypertension, and cardiac failure) even though there is no clear evidence of its effectiveness on survival or alleviation of symptoms. ${ }^{3}$ In many diseases, chronic respiratory insufficiency and hypoxemia develop at the late stages of the disease, when the life expectancy of the patient is limited. ${ }^{8-10}$ Therefore, the clinical decision to initiate LTOT should be concomitantly considered with timely advance care planning and palliative care consultation. However, the individual prognosis in patients who receive LTOT is difficult to estimate due to considerable variation in the rate of progression among different pulmonary diseases and to the effects of other factors, such as age and comorbidities. At the moment, there is little information regarding which factors among patients on LTOT are associated with their prognosis in clinical practice. Our aim was to study the factors associated with survival in subjects for whom LTOT was initiated in a real-life setting.

\section{Methods}

\section{Patients}

All the patients who were started on LTOT in the respiratory insufficiency unit of the Tampere University Hospital from January 1, 2012, to December 31, 2015, were included in this study. The subjects were followed up until death or December 31, 2017.

\section{Data Collection}

All medical records, including notes of the nurses, were reviewed. The collected characteristics of the subjects included age, sex, weight, height, living conditions, working status, smoking status, medication, diagnoses, and date of death. Results of spirometry, arterial blood gases, and nocturnal or daytime oxygen saturation were recorded as well. According to the comorbidities, the Charlson comorbidity index was calculated for each subject based on the disease severity. ${ }^{11,12}$ For subjects with COPD, the Global Initiative for Chronic Obstructive Lung Disease stages for the severity of the air-flow limitation were defined. ${ }^{13}$ The subjects were considered to require assistance in activities of daily living (ADL) if they needed continuous help from a family member who worked as a caregiver, received home care services (eg, dietary services, ablution, dressing, or medication), or permanently stayed in a nursing home or

\section{QUICK LOOK}

\section{Current knowledge}

Long-term oxygen therapy (LTOT) prolongs survival in patients with COPD and severe hypoxemia. It is also used in several other diseases that cause hypoxemia, although there is no clear evidence of its effectiveness. The need for LTOT is considered a marker of advanced disease, but there is no current knowledge about which factors are associated with poor survival among these patients in a real-life setting.

\section{What this paper contributes to our knowledge}

The overall survival of subjects with LTOT was poor but varied greatly. The subjects who had interstitial lung disease as the primary disease that caused the need for LTOT or needed help in activities of daily living were more likely to die during the first year after the onset of LTOT. The Charlson comorbidity index was associated with worse overall survival as well.

community hospital. The disease that caused the need for initiation of LTOT was defined as the primary disease, whereas all other diseases were considered comorbidities.

\section{Statistical Analysis}

Based on a visual estimation, many of the distributions were non-normal, and nonparametric tests were used. A comparison of different groups was performed by using the Mann-Whitney Test for continuous variables and the Pearson chi-square test or Fisher exact test for categorical variables. The Kaplan-Meier method and the Cox proportional hazard regression analysis were used for survival estimation. Statistical significance was set as $P<.05$. Analyses were performed with IBM SPSS Statistics version 22.0 (Armonk, NY).

\section{Ethical Consideration}

This study was approved by the regional ethics committee of Tampere University Hospital, Finland (approval R15180/1.12.2015).

\section{Results}

Altogether 195 subjects started LTOT during the study period and were included. Characteristics of the subjects are shown in Table 1. Most subjects (68\%) smoked before the start of LTOT, and the median pack-years among smokers was 40 (interquartile range [IQR] 20-50). Almost two 



Fig. 1. A: Overall survival after the initiation of long-term oxygen therapy in the total study sample. B: In subjects ages $>75 \mathrm{y}$ (median 1.4 [IQR 0.4-3.1] y) and $\leq 75$ y (median 2.8 [IQR 1.1-NA] y), $P=.001$. C: According to primary disease, COPD (median 2.4 [IQR 1.1-4.5] y), ILD (median 0.9 [IQR 0.4-2.2] y), or other (median 3.2 [IQR 1.1-5.8] y), $P<.001$ between COPD and ILD. D: According to the need for help in activities of daily living, did not need help (median 3.3 [IQR 1.7-5.8] y) and needed help (median 1.2 [QR 0.4-2.8] y), $P<.001$. IQR = interquartile range; ILD = interstitial lung disease, NA = not available.

disease as the underlying need for LTOT remained independently associated with shorter survival (Table 3).

\section{Discussion}

We presented a real-life study in an unselected sample of subjects for whom LTOT was prescribed and initiated. The median survival of the total sample was $\sim 2 \mathrm{y}$, but this varied significantly among different subject groups. The subjects with interstitial lung disease had significantly shorter survival than did those with COPD, and more than half of the subjects with interstitial lung disease died during the first year after initiation of LTOT. The need for help in ADL, a higher Charlson comorbidity index, and interstitial lung disease as a primary disease that necessi- tated LTOT were independently associated with poorer survival.

The subjects on LTOT who needed constant help with ADL had worse overall and 1-y survival compared with those who managed by themselves or needed only occasional help. It seemed that the limited general performance status better reflected the risk of death than did lung function or blood gas levels in a nonselected subject sample with LTOT. To our knowledge, this was the first study to show the association between the need for help in ADL and survival among subjects with LTOT, although the need for help in ADL is associated with worse survival among subjects with interstitial lung disease or COPD in general. ${ }^{14,15}$ Leuchte et al ${ }^{14}$ showed that subjects with IPF (with or without LTOT) who 


\section{SuRvival OF SubJECTS ON LTOT}

Table 2. Subject Characteristics According to 1 Year Survival After the Initiation of LTOT

\begin{tabular}{|c|c|c|c|}
\hline Characteristic & Died during the 1 st Year & Survived Over 1 Year & $P^{*}$ \\
\hline Total, $n$ & 56 & 139 & \\
\hline Sex, $n(\%)$ & & & .17 \\
\hline Males & $39(69.6)$ & $82(59.0)$ & \\
\hline Females & $17(30.4)$ & $57(41.0)$ & \\
\hline \multicolumn{4}{|l|}{ Age } \\
\hline Median (IQR) y & $78.5(68.0-85.0)$ & $72.0(66.0-79.0)$ & .004 \\
\hline$\leq 75 \mathrm{y}, n(\%)$ & $23(41.1)$ & $90(64.7)$ & .002 \\
\hline$>75 \mathrm{y}, n(\%)$ & $33(58.9)$ & $49(35.3)$ & \\
\hline Body mass index, median (IQR) $\mathrm{kg} / \mathrm{m}^{2}$ & $25.5(22.9-29.9)$ & $28.6(23.2-33.9)$ & .03 \\
\hline Need for help with ADL, $n(\%)$ & & & $<.001$ \\
\hline No & $17(30.4)$ & $88(63.3)$ & \\
\hline Yes & $39(69.6)$ & $51(36.7)$ & \\
\hline Smoking status, $n(\%)$ & & & .61 \\
\hline Never-smoker & $21(37.5)$ & $39(28.1)$ & \\
\hline Ex-smoker & $35(62.5)$ & $98(70.5)$ & \\
\hline Smoker & $0(0.0)$ & $1(0.7)$ & \\
\hline Not known & $0(0.0)$ & $1(0.7)$ & \\
\hline \multicolumn{4}{|l|}{$\mathrm{FEV}_{1}$} \\
\hline Median (IQR) L & $1.47(1.04-1.95)$ & $1.28(0.91-1.79)$ & .10 \\
\hline Median (IQR) $\%$ of predicted & $57.0(40.0-66.0)$ & $47.0(35.0-63.0)$ & .039 \\
\hline \multicolumn{4}{|l|}{ FVC } \\
\hline Median (IQR) L & $2.32(1.91-3.00)$ & $2.56(1.82-3.09)$ & .58 \\
\hline Median (IQR) $\%$ of predicted & $70.0(55.8-86.3)$ & $72.5(57.3-83.8)$ & .77 \\
\hline $\mathrm{P}_{\mathrm{aO}_{2}}$ with room air, median (IQR) $\mathrm{mm} \mathrm{Hg}$ & $54(46.5-58.5)$ & $57.4(48.0-54.8)$ & .25 \\
\hline Oxygen flow, median (IQR) L/min & $2.0(1.0-2.0)$ & $1.5(1.0-2.0)$ & .54 \\
\hline Primary disease that caused the need for LTOT, $n(\%)$ & & & $<.001$ \\
\hline COPD & $19(33.9)$ & $73(52.5)$ & .02 \\
\hline Interstitial lung disease & $24(42.9)$ & $20(14.4)$ & $<.001$ \\
\hline Heart diseases & $8(14.3)$ & $10(7.2)$ & .12 \\
\hline Obesity-hypoventilation syndrome & $0(0.0)$ & $18(12.9)$ & .005 \\
\hline Other & $5(8.9)$ & $18(12.9)$ & .43 \\
\hline \multicolumn{4}{|l|}{ Comorbidities, $n(\%)$} \\
\hline Hypertension & $34(60.7)$ & $86(61.9)$ & .88 \\
\hline Heart diseases & $35(62.5)$ & $77(55.4)$ & .36 \\
\hline Cerebrovascular diseases & $4(7.1)$ & $9(6.5)$ & $>.99$ \\
\hline Diabetes & $18(32.1)$ & $42(30.2)$ & .79 \\
\hline COPD & $7(12.5)$ & $11(7.9)$ & .32 \\
\hline Asthma & $4(7.1)$ & $23(16.5)$ & .09 \\
\hline Sleep apnea & $9(16.1)$ & $29(20.9)$ & .45 \\
\hline Neurologic diseases & $10(17.9)$ & $23(16.5)$ & .83 \\
\hline Renal diseases & $7(12.5)$ & $11(7.9)$ & .32 \\
\hline Rheumatic diseases & $5(8.9)$ & $13(9.4)$ & .93 \\
\hline Cancer & $11(19.6)$ & $27(19.4)$ & .97 \\
\hline Others & $13(23.2)$ & $36(25.9)$ & .70 \\
\hline No comorbidities & $2(3.6)$ & $7(5.0)$ & $>.99$ \\
\hline Charlson comorbidity index, median (IQR) & $2.0(1.0-3.0)$ & $2.0(1.0-2.0)$ & .09 \\
\hline $\begin{array}{l}\mathrm{LTOT}=\text { long-term oxygen therapy } \\
\mathrm{IQR}=\text { interquartile range } \\
\mathrm{ADL}=\text { activities of daily living }\end{array}$ & & & \\
\hline
\end{tabular}

needed help in ADL had worse survival compared to those who didn't need help in ADL.

Similarly, in the subjects with COPD (no mention of the possible use of LTOT), difficulties in ADL were associ- ated with worse survival in a study by Liu et al. ${ }^{15}$ The need for help in ADL probably reflected poor performance status and high morbidity, which are features of poor prognosis in many diseases. ${ }^{16}$ In the current study, $83.3 \%$ of 


\section{SuRvival of SubJeCts on LTOT}

Table 3. Factors Associated With Survival in Cox Regression Analysis

\begin{tabular}{|c|c|c|c|c|}
\hline \multirow{2}{*}{ Factor } & \multicolumn{2}{|c|}{ Univariate Analysis } & \multicolumn{2}{|c|}{ Multivariate Analysis* } \\
\hline & $\operatorname{HR}(95 \% \mathrm{Cl})$ & $P$ & $\operatorname{HR}(95 \% \mathrm{Cl})$ & $P$ \\
\hline \multicolumn{5}{|l|}{ Sex } \\
\hline Females & Ref. & & ND & \\
\hline Males & $1.02(0.72-1.45)$ & .92 & ND & ND \\
\hline Age (continuous) & $1.03(1.01-1.05)$ & .001 & ND & ND \\
\hline \multicolumn{5}{|l|}{ Age (categorical) } \\
\hline$\leq 75 \mathrm{y}$ & Ref. & & Ref. & \\
\hline$>75 y$ & $1.81(1.29-2.55)$ & .001 & $1.31(0.90-1.90)$ & .15 \\
\hline Body mass index, $\mathrm{kg} / \mathrm{m}^{2}$ & $0.97(0.95-0.99)$ & .007 & $0.97(0.94-1.01)$ & .11 \\
\hline \multicolumn{5}{|l|}{ Need for help in ADL } \\
\hline No & Ref. & & Ref. & \\
\hline Yes & $2.22(1.57-3.14)$ & $<.001$ & $2.10(1.44-3.06)$ & $<.001$ \\
\hline \multicolumn{5}{|l|}{ Smoking status } \\
\hline Never-smoker & Ref. & & ND & \\
\hline Ex-smoker & $0.98(0.68-1.42)$ & .92 & ND & ND \\
\hline \multicolumn{5}{|l|}{$\mathrm{FEV}_{1}$} \\
\hline $\mathrm{L}$ & $1.11(0.84-1.48)$ & .47 & ND & ND \\
\hline$\%$ of predicted & $1.01(1.00-1.02)$ & .09 & ND & ND \\
\hline \multicolumn{5}{|l|}{$\mathrm{FVC}$} \\
\hline $\mathrm{L}$ & $0.96(0.78-1.19)$ & .73 & ND & ND \\
\hline$\%$ of predicted & $1.00(0.99-1.01)$ & .48 & ND & ND \\
\hline $\mathrm{P}_{\mathrm{aO}_{2}}$ with room air, $\mathrm{mm} \mathrm{Hg}$ & $7.7(6.15-9.53)$ & .86 & ND & ND \\
\hline Oxygen flow, L/min & $0.99(0.82-1.18)$ & .87 & ND & ND \\
\hline \multicolumn{5}{|c|}{ Primary disease that caused the need for LTOT } \\
\hline COPD & Ref. & & Ref. & \\
\hline Interstitial lung disease & $2.20(1.46-3.29)$ & $<.001$ & $2.08(1.36-3.17)$ & .001 \\
\hline Heart diseases & $1.25(0.65-2.38)$ & .50 & $1.33(0.69-2.57)$ & .40 \\
\hline Obesity-hypoventilation syndrome & $0.42(0.19-0.92)$ & .031 & $0.49(0.20-1.24)$ & .13 \\
\hline Other & $0.98(0.57-1.73)$ & .98 & $1.08(0.60-1.94)$ & .81 \\
\hline \multicolumn{5}{|l|}{ Comorbidities $\dagger$} \\
\hline Hypertension & $0.93(0.66-1.31)$ & .68 & ND & ND \\
\hline Heart diseases & $1.49(1.04-2.12)$ & .03 & $0.94(0.63-1.39)$ & .75 \\
\hline Cerebrovascular diseases & $1.66(0.92-3.02)$ & .09 & ND & ND \\
\hline Diabetes & $1.03(0.71-1.49)$ & .88 & ND & ND \\
\hline COPD & $1.11(0.63-1.97)$ & .72 & ND & ND \\
\hline Asthma & $0.73(0.43-1.23)$ & .24 & ND & ND \\
\hline Sleep apnea & $0.40(0.23-0.70)$ & .001 & $1.54(0.84-2.83)$ & .16 \\
\hline Neurologic diseases & $1.53(1.00-2.32)$ & .048 & $1.00(0.63-1.56)$ & .98 \\
\hline Renal diseases & $1.64(0.99-2.73)$ & .057 & ND & ND \\
\hline Rheumatic diseases & $0.66(0.35-1.27)$ & .21 & ND & ND \\
\hline Cancer & $1.07(0.69-1.65)$ & .78 & ND & ND \\
\hline Others & $1.20(0.81-1.75)$ & .36 & ND & ND \\
\hline No comorbidities & $0.98(0.46-2.13)$ & .98 & ND & ND \\
\hline Charlson comorbidity index & $1.24(1.11-1.39)$ & $<.001$ & $1.26(1.11-1.43)$ & $<.001$ \\
\hline $\begin{array}{l}\text { * Variables significantly associated with survival } \\
\dagger \text { HR in comparison with subjects without the con } \\
\text { HR = hazard ratio } \\
\text { Ref. = Reference } \\
\text { ND = no data } \\
\text { ADL = activities of daily living } \\
\text { LTOT = long-term oxygen therapy }\end{array}$ & , and all primary diagnos & & & \\
\hline
\end{tabular}


the patients who couldn't perform any kind of lung function measurements (spirometry nor microspirometry) and $72.4 \%$ of those who could only perform microspirometry were in need of help with ADL, which was probably associated with poor performance status and which prevented the completion of spirometry. Due to this association, our statistical analysis may not have been sensitive enough to detect the association between poor lung function and poor survival. Further, the lack of an association between baseline $\mathrm{P}_{\mathrm{aO}_{2}}$ and survival might have been because the baseline $\mathrm{P}_{\mathrm{aO}_{2}}$ was not necessarily related to the forthcoming progression rate of the disease or deterioration of the patient.

In addition, a relatively high proportion of our subjects (46\%) who started LTOT needed help with ADL, which, to our knowledge, has not previously been clearly reported. In a study by Okubadejo et al, ${ }^{17}$ subjects with advanced COPD and on LTOT were reported as less independent with ADL than those not on LTOT, but the actual proportion of subjects who needed help with ADL was not reported. Thus, coping with ADL should be discerned in every patient who starts LTOT as an estimation of survival and social support.

The median survival of the subjects with COPD who received LTOT was reported to be approximately $2-3$ y, 8,9 whereas, in a recent study on subjects with interstitial lung disease and on LTOT, the survival was only 8.4 months. ${ }^{10}$ Our results were well in line with these numbers, but we were able to show this difference in a single center clinical study as well. More than half of our subjects with interstitial lung disease had a diagnosis of IPF, which further explained the poor survival of this subject group because the median survival after a diagnosis of IPF is only approximately $2-4$ y. ${ }^{18-22}$ Our results highlighted the importance of a primary diagnosis in patients with LTOT as a clinical tool in estimating prognosis. Further, there is no clear evidence for the beneficial role of LTOT on survival or symptom alleviation in patients with interstitial lung disease or IPF. ${ }^{23}$

In the univariate analysis, $\mathrm{FEV}_{1}$ was significantly higher in the subjects who died during the first year, but this was not significant in the multivariate analysis. This was probably explained because the subjects with interstitial lung disease had shorter survival than those with COPD, whereas COPD as an obstructive disease is associated with lower $\mathrm{FEV}_{1}$. Our results were in line with previous studies that showed that, although the decline in lung function indices does predict worse survival in interstitial lung disease and COPD, impaired exercise capacity is more closely associated with mortality. ${ }^{24,25}$

Also, younger age and higher BMI in our subjects with LTOT were associated with better survival in univariate but not in multivariate analysis. We suggest that the better survival in subjects with highed BMI was partly explained by the survivors being more likely to have obesity-hypoventilation syndrome rather than a progressive lung disease as the main reason for initiation of LTOT. Unfortunately, the small number of subjects with obesity-hypoventilation syndrome prevented us from evaluating this group in detail. Most of the subjects with obesityhypoventilation syndrome also had noninvasive ventilation or CPAP in addition to LTOT, as recommended in the guidelines. ${ }^{3}$ However, lower BMI has been associated with poorer survival in several advanced diseases, such as COPD $^{5,26-28}$ and IPF, ${ }^{29}$ which might also explain the association between shorter survival and lower BMI in univariate analysis.

Most of our subjects had comorbidities, of which heart and neurologic diseases were associated with shorter overall survival in univariate analysis. In previous studies, comorbidities were shown to be associated with impaired survival in COPD and interstitial lung disease. ${ }^{30,31}$ However, other factors, such as lung function and poor performance status, have been more closely related to prognosis. ${ }^{32}$ Similarly, the relation of any single comorbidity to mortality disappeared in the multivariate analysis of our data, which indicated that other factors were more important regarding survival. The multimorbidity index (Charlson comorbidity index), in turn, was associated with shorter survival in univariate analysis and also in multivariate analysis. We suggested that the total burden of comorbidities might be more closely related to poor survival than a single disease as a comorbidity.

Advance care planning and palliative care are recommended as integral parts of the treatment of patients with advanced cardiopulmonary diseases. ${ }^{13,33}$ However, recent studies showed that advance care planning conversations are uncommon in patients with chronic respiratory disease. ${ }^{34,35}$ The benefits of integrated palliative care in patients with COPD or interstitial lung disease include better control of dyspnea, fewer emergency department visits during the last year of life, and an opportunity for patients to die at home instead of in the hospital. ${ }^{36,37}$ However, a recent study showed that subjects with interstitial lung disease and on LTOT still receive lower-quality end-of-life care compared with subjects with cancer. ${ }^{15}$ One of the key questions in clinical practice is the suitable timing of advance care planning and integrated palliative care. The need for LTOT is usually a sign of advanced disease, but our study showed the heterogeneity of subjects on LTOT. Based on our results, the initiation of LTOT should be considered a trigger for advance care planning discussions and palliative care consultations, especially in patients with interstitial lung disease or those who continuously need help with ADL. 


\section{SuRvival of SubJeCts ON LTOT}

\section{Strengths and Limitations}

We presented data on all subjects who were started on LTOT in a single university hospital during the study period. This allowed us to compare prognostic factors in an unselected subject sample and to give practical information for physicians who are taking care of the patients with LTOT. However, the study sample was relatively small, and, therefore, statistical power may not be sufficient to detect weak associations, especially among subjects with diseases other than COPD and interstitial lung disease (eg, obesity-hypoventilation syndrome). Due to the retrospective nature of the study, we were not able to study all the possible factors that influenced the prognosis of the subjects. The need for help with ADL was defined by using strict criteria, which probably found subjects who needed major help but might have omitted those with lesser impairment in self-care. Further, our analysis included data on important factors, for example, lung function, only at baseline, and we thus were not able to study the predictive ability of changes in these variables during LTOT.

\section{Conclusions}

The median overall survival among a real-life sample of subjects started on LTOT was relatively short but with considerable variation. The most important clinical predictors of poor survival were interstitial lung disease as the underlying disease that necessitated LTOT, the need for help with ADL, and multiple comorbidites. We suggest that these factors could be used by clinicians as triggers for advance care planning and palliative care consultations.

\section{REFERENCES}

1. Continuous or nocturnal oxygen therapy in hypoxemic chronic obstructive lung disease: a clinical trial. Nocturnal Oxygen Therapy Trial Group. Ann Intern Med 1980;93(3):391-398.

2. Long term domiciliary oxygen therapy in chronic hypoxic cor pulmonale complicating chronic bronchitis and emphysema. Report of the Medical Research Council Working Party. Lancet 1981;1(8222): 681-686.

3. Hardinge M, Annandale J, Bourne S, Cooper B, Evans A, Freeman $\mathrm{D}$, et al. British Thoracic Society guidelines for home oxygen use in adults. Thorax 2015;70(Suppl 1):i1-43.

4. COPD Working Group. Long-term oxygen therapy for patients with chronic obstructive pulmonary disease (COPD): an evidence-based analysis. Ont Health Technol Assess Ser 2012;12(7):1-64.

5. Górecka D, Gorzelak K, Sliwiński P, Tobiasz M, Zieliński J. Effect of long-term oxygen therapy on survival in patients with chronic obstructive pulmonary disease with moderate hypoxaemia. Thorax 1997;52(8):674-679.

6. Long-Term Oxygen Treatment Trial Research Group, Albert RK, Au DH, Blackford AL, Casaburi R, Cooper JA, Jr, et al. A Randomized Trial of Long-Term Oxygen for COPD with Moderate Desaturation. N Engl J Med 2016;375(17):1617-1627.
7. Ekström M, Ringbaek T. Which patients with moderate hypoxemia benefit from long-term oxygen therapy? Ways forward. Int J Chron Obstruct Pulmon Dis 2018;13:231-235.

8. Ahmadi Z, Sundh J, Bornefalk-Hermansson A, Ekström M. Longterm oxygen therapy $24 \mathrm{vs} 15 \mathrm{~h} /$ day and mortality in chronic obstructive pulmonary disease. PLoS One 2016;11(9):e0163293.

9. Gulbas G, Gunen H, In E, Kilic T. Long-term follow-up of chronic obstructive pulmonary disease patients on long-term oxygen treatment. Int J Clin Pract 2012;66(2):152-157.

10. Ahmadi Z, Wysham NG, Lundström S, Janson C, Currow DC, Ekström M. End-of-life care in oxygen-dependent ILD compared with lung cancer: a national population-based study. Thorax 2016;71(6): 510-516.

11. Charlson ME, Pompei P, Ales KL, MacKenzie CR. A new method of classifying prognostic comorbidity in longitudinal studies: development and validation. J Chronic Dis 1987;40(5):373-383.

12. Charlson M, Szatrowski TP, Peterson J, Gold J. Validation of a combined comorbidity index. J Clin Epidemiol 1994;47(11):12451251.

13. From the global strategy for the diagnosis, management and prevention of COPD, global initiative for chronic obstructive lung disease (GOLD) 2017. Available at https://goldcopd.org. Accessed March 24, 2018.

14. Leuchte HH, Mernitz P, Baezner C, Baumgartner RA, von Wulffen W, Neurohr C, Behr J. Self-report daily life activity as a prognostic marker of idiopathic pulmonary fibrosis. Respiration 2015;90(6): 460-467.

15. Liu Y, Croft JB, Anderson LA, Wheaton AG, Presley-Cantrell LR, Ford ES. The association of chronic obstructive pulmonary disease, disability, engagement in social activities, and mortality among US adults aged 70 years or older, 1994-2006. Int J Chron Obstruct Pulmon Dis 2014;9:75-83.

16. Stineman MG, Xie D, Pan Q, Kurichi JE, Zhang Z, Saliba D, et al. All-cause 1-, 5-, and 10-year mortality in elderly people according to activities of daily living stage. J Am Geriatr Soc 2012;60(3):485492.

17. Okubadejo AA, O'Shea L, Jones PW, Wedzicha JA. Home assessment of activities of daily living in patients with severe chronic obstructive pulmonary disease on long-term oxygen therapy. Eur Respir J 1997;10(7):1572-1575.

18. Hubbard R, Johnston I, Britton J. Survival in patients with cryptogenic fibrosing alveolitis: a population-based cohort study. Chest 1998;113(2):396-400.

19. Nicholson AG, Colby TV, du Bois RM, Hansell DM, Wells AU. The prognostic significance of the histologic pattern of interstitial pneumonia in patients presenting with the clinical entity of cryptogenic fibrosing alveolitis. Am J Respir Crit Care Med 2000;162(6):22132217.

20. King TE Jr, Schwarz MI, Brown K, Tooze JA, Colby TV, Waldron $\mathrm{JA} \mathrm{Jr}$, et al. Idiopathic pulmonary fibrosis: relationship between histopathologic features and mortality. Am J Respir Crit Care Med 2001;164(6):1025-1032.

21. Mura M, Porretta MA, Bargagli E, Sergiacomi G, Zompatori M, Sverzellati N, et al. Predicting survival in newly diagnosed idiopathic pulmonary fibrosis: a 3-year prospective study. Eur Respir J 2012;40(1):101-109.

22. King TE Jr, Pardo A, Selman M. Idiopathic pulmonary fibrosis. Lancet 2011;378(9807):1949-1961.

23. Bell EC, Cox NS, Goh N, Glaspole I, Westall GP, Watson A, Holland AE. Oxygen therapy for interstitial lung disease: a systematic review. Eur Respir Rev 2017;26(143). pii: 160080.

24. Pinto-Plata VM, Cote C, Cabral H, Taylor J, Celli BR. The 6-min walk distance: change over time and value as a predictor of survival in severe COPD. Eur Respir J 2004;23(1):28-33. 


\section{SuRvival of SubJects on LTOT}

25. Puhan MA, Siebeling L, Zoller M, Muggensturm P, ter Riet G. Simple functional performance tests and mortality in COPD. Eur Respir J 2013;42(4):956-963.

26. Cao C, Wang R, Wang J, Bunjhoo H, Xu Y, Xiong W. Body mass index and mortality in chronic obstructive pulmonary disease: a metaanalysis. PLoS One 2012;7(8):e43892.

27. Guo Y, Zhang T, Wang Z, Yu F, Xu Q, Guo W, et al. Body mass index and mortality in chronic obstructive pulmonary disease: a dose-response meta-analysis. Medicine (Baltimore) 2016;95(28):e4225.

28. Marti S, Muñoz X, Rios J, Morell F, Ferrer J. Body weight and comorbidity predict mortality in copd patients treated with oxygen therapy. Eur Respir J 2006;27(4):689-696.

29. Alakhras M, Decker PA, Nadrous HF, Collazo-Clavell M, Ryu JH. Body mass index and mortality in patients with idiopathic pulmonary fibrosis. Chest 2007;131(5):1448-1453.

30. Ekström MP, Jogréus C, Ström KE. Comorbidity and sex-related differences in mortality in oxygen-dependent chronic obstructive pulmonary disease. PLoS One 2012;7(4):e35806.

31. Schwarzkopf L, Witt S, Waelscher J, Polke M, Kreuter M. Associations between comorbidities, their treatment and survival in patients with interstitial lung diseases - a claims data analysis. Respir Res 2018;19(1):73.

32. Celli BR, Cote CG, Marin JM, Casanova C, Montes de Oca M, Mendez RA, et al. The body-mass index, airflow obstruction, dys- pnea, and exercise capacity index in chronic obstructive pulmonary disease. N Engl J Med 2004;350(10):1005-1012.

33. Selecky PA, Eliasson CA, Hall RI, Schneider RF, Varkey B, McCaffree DR, American College of Chest Physicians. Palliative and end-of-life care for patients with cardiopulmonary diseases: American College of Chest Physicians Position Statement. Chest 2005; 128(5):3599-3610.

34. Jabbarian LJ, Zwakman M, van der Heide A, Kars MC, Janssen DJA, van Delden JJ, et al. Advance care planning for patients with chronic respiratory diseases: a systematic review of preferences and practices. Thorax 2018;73(3):222-230.

35. Rush B, Hertz P, Bond A, McDermid RC, Celi LA. Use of palliative care in patients with end-stage COPD and receiving home oxygen: national trends and barriers to care in the United States. Chest 2017; 151(1):41-46.

36. Kalluri M, Claveria F, Ainsley E, Haggag M, Armijo-Olivo S, Richman-Eisenstat J. Beyond idiopathic pulmonary fibrosis diagnosis: multidisciplinary care with an early integrated palliative approach is associated with a decrease in acute care utilization and hospital deaths. J Pain Symptom Manage 2018;55(2):420-426.

37. Brinkman-Stoppelenburg A, Rietjens JA, van der Heide A. The effects of advance care planning on end-of-life care: a systematic review. Palliat Med 2014;28(8):1000-1025. 